Systematic Review

\title{
Effectiveness of Percutaneous Adhesiolysis in Post Lumbar Surgery Syndrome: A Systematic Analysis of Findings of Systematic Reviews
}

Laxmaiah Manchikanti, MD ${ }^{1,2}$, Amol Soin, $\mathrm{MD}^{3}$, Mark V. Boswell, MD, $\mathrm{PhD}^{4}$,

Alan D. Kaye, MD, PhD², Mahendra Sanapati, MD'1, and Joshua A. Hirsch, MD

From: ${ }^{1}$ Pain Management Centers of America, Paducah, KY and Evansville, IN; ${ }^{2}$ LSU Health Science Center, New Orleans, LA; ${ }^{3}$ Ohio Pain Clinic, Centerville, $\mathrm{OH}$, Wright State University, Dayton, $\mathrm{OH}$, University of Pikeville, Pikeville, KY; ${ }^{4}$ University of Toledo College of Medicine and Life Sciences, Toledo, $\mathrm{OH}$;

5Massachusetts General Hospital and Harvard Medical School, Boston, MA

Address Correspondence: Laxmaiah Manchikanti, MD 67 Lakeview Drive

Paducah, Kentucky 42001

E-mail: drlm@thepainmd.com

Disclaimer: There was no external funding in the preparation of this manuscript. Conflict of interest: Each author

certifies that he or she, or a member of his or her immediate

family, has no commercial association (i.e., consultancies, stock ownership, equity interest, patent/licensing arrangements, etc.) that might pose a conflict of interest in connection with the

submitted manuscript.

Manuscript received: 05-30-2019

Revised manuscript received: o6-15-2019

Accepted for publication: 06-25-2019

Free full manuscript: www.painphysicianjournal.com
Background: Post lumbar surgery syndrome is common and often results in chronic, persistent pain and disability, which can lead to multiple interventions. After failure of conservative treatment, either surgical treatment or a nonsurgical modality of treatment such as epidural injections, percutaneous adhesiolysis are often contemplated in managing post lumbar surgery syndrome. Multiple previous systematic reviews have reached discordant conclusions about the level of evidence for the effectiveness of percutaneous adhesiolysis in managing post lumbar surgery syndrome and other conditions.

Study Design: A systematic review of previously published systematic reviews assessing efficacy of percutaneous adhesiolysis in managing post lumbar surgery syndrome.

Objective: To evaluate the value and validity of previous systematic reviews performed after 2015 on effectiveness of percutaneous adhesiolysis in managing chronic refractory low back and lower extremity pain secondary to post lumbar surgery syndrome.

Methods: Previous systematic reviews on percutaneous adhesiolysis were evaluated. The quality of each systematic review was assessed by Preferred Reporting Items for Systematic Reviews and Meta-Analyses (PRISMA) and A Measurement Tool to Assess Systematic Reviews (AMSTAR).

The randomized trials included in the available systematic reviews were assessed by Cochrane review criteria and Interventional Pain Management techniques - Quality Appraisal of Reliability and Risk of Bias Assessment (IPM-QRB) for methodologic quality.

Data sources included relevant systematic reviews and the randomized trials included in those systematic reviews published since 2015 with searches of PubMed, Cochrane reviews, and Google Scholar through February 2019

Outcome Measures: Outcome measures were significant improvement defined as 50\% pain relief and improvement in functional status. Short-term efficacy was defined as improvement of 6 months or less, whereas long-term efficacy was defined as more than 6 months.

Results: Three systematic reviews and 4 randomized controlled trials (RCTs) of post lumbar surgery syndrome with chronic refractory low back and lower extremity pain showed notable evidence of significant pain relief. Only one systematic review, which was of low quality with inappropriate analysis, showed lack of evidence.

Conclusion: Overall, the present analysis shows Level I evidence for percutaneous adhesiolysis based on significant evidence from published RCTs and 3 of the 4 systematic reviews.

Key words: Post lumbar surgery syndrome, epidural fibrosis, percutaneous adhesiolysis, systematic reviews, randomized controlled trials

Pain Physician 2019: 22:307-322 
M anchikanti et al (1) described that progress and innovations in health care are measured by evidence-based medicine (EBM), systematic reviews, and meta-analysis. A systematic review is defined as, "the application of scientific strategies that limit bias by the systematic assembly, critical appraisal, and synthesis of all relevant studies on a specific topic." Thus, systematic reviews are aimed at acquiring all evidence involving a reproducible and thorough search of the literature and critical evaluation of eligible studies. A systematic review can be either qualitative, in which all eligible studies are summarized, or quantitative, known as meta-analysis with data from all individual studies are statistically combined (2). Consequently, not all systematic reviews may result in meta-analysis. However, while it is ideal to perform a qualitative review of the evidence prior to quantitative review, some meta-analysis may not have been preceded by a systematic review. Further, qualitative analysis is essential to ensure that findings are not affected by selection bias (2). Conducting a thorough systematic review, specifically with metaanalysis, is a cumbersome and multistep process that involves carefully designing a rigorous protocol in accordance with established guidelines for conducting systematic reviews, such as Preferred Reporting Items for Systematic Reviews and Meta-Analyses (PRISMA) and performing robust statistical analysis $(3,4)$.

In recent years, there have been large volumes of research conducted and published, often with conflicting results, specifically in interventional pain management (5-39). The literature suggests that differences in conclusions are based on physician preference, lack of understanding of the basis of procedural aspects, lack of clinical experience, overenthusiasm to publish, publication of negative studies more frequently than positive studies, conflicts, and confluence of interest (38-46). Indeed, with the mass production of redundant, misleading, and conflicted systematic reviews and metaanalysis (16), the value and sustainability of EBM has been questioned (47-58). The study of methodological and reporting quality of systematic reviews published in the highest-ranking journals in the field of pain by Riado Minguez et al (53) showed there was no improvement in the methodological and reporting quality of systematic reviews before or after the publication of A Measurement Tool to Assess Systematic Reviews (AMSTAR) (59) and PRISMA checklists (3). This review included multiple journals from Anesthesiology and Pain across the globe, but has not found any systematic reviews to be included from the journal Pain Medicine. Pain Physician published a large number of systematic reviews of moderate to high quality. Further, Ross et al (54) in assessing methodologic quality of systematic reviews referenced in clinical practice guidelines for the treatment of opioid use disorder concluded that underperforming areas in AMSTAR included conflicts of interest, funding, and publication bias, whereas in PRISMA, they found protocol registration and risk of bias as issues of concern.

Consequently, systematic reviews may vary, and a systematic review does not guarantee high methodological and reporting rigor as shown by Riado Minguez et al (53), Ross et al (54), and others (16,55-58). Multiple systematic reviews have been published assessing percutaneous adhesiolysis, an interventional procedure utilized for recalcitrant, resistant conditions involving spinal pain, specifically in spinal stenosis, post lumbar surgery syndrome, and recalcitrant degenerative disc disease including disc herniation (17,33,60-62). These systematic reviews $(17,30,60-62)$ have been performed with inclusion of randomized controlled trials (RCTs) (63-69), specifically in failed back surgery, spinal stenosis, and disc herniation with discordant results. Cho et al (33) also evaluated the quality of systematic reviews performed in adhesiolysis for post lumbar surgery syndrome, with inclusion of other systematic reviews (33) and comparison of the evidence with RCTs $(63,64,70,71)$ and systematic reviews of spinal cord stimulation $(11,72)$. Since publication of these systematic reviews, 3 additional RCTs have been published (73-75) with 2 of them in post lumbar surgery syndrome $(74,75)$. Of the 4 systematic reviews performed since 2015, 3 of them $(17,33,60,61)$ concentrated on post lumbar surgery syndrome, whereas one (17) assessed all conditions with inclusion of observational studies. However, meta-analysis was performed in only one systematic review by Helm et al (17), which showed significant improvement qualitatively and quantitatively in post lumbar surgery syndrome and spinal stenosis. In contrast, Cho et al (33) showed higher level of evidence for adhesiolysis, than spinal cord stimulation. The reasons for discordant results may relate to a lack of understanding of the procedure, lack of understanding of principles of EBM with importance of utilization of clinical expertise, and finally confluence of interest $(16,45-50)$.

Therefore, this assessment was undertaken to systematically review the evidence derived from systematic reviews of percutaneous adhesiolysis and determine the appropriateness in post lumbar surgery syndrome. 


\section{Methods}

This systematic review analyzed the data from systematic reviews and published primary studies. Thus, no patient data were included. Consequently, no approval from Institutional Review Board (IRB) was required.

\section{Inclusion Criteria}

We analyzed adhesiolysis-related systematic reviews with or without meta-analysis. The included manuscripts were limited to study of post lumbar surgery syndrome with or without inclusion of other conditions.

\section{Exclusion Criteria}

Duplicate systematic reviews, narrative reviews, guidelines, and the RCTs not included in the systematic reviews were excluded. The RCTs which failed to include at least $75 \%$ of the patients with post lumbar surgery syndrome were excluded.

\section{Literature Search}

The MEDLINE database from 2015 to 2018 was searched using an advanced search for systematic reviews with or without meta-analysis, assessing post lumbar surgery syndrome.

\section{Data Extraction and Management}

In a standardized, unblinded manner, 2 review authors independently developed search criteria, searched for the literature, and selected the manuscripts. They also extracted the included studies in the appropriate systematic reviews. Two review authors also assessed risk of bias and methodologic quality assessment, scoring of AMSTAR, PRISMA, and Scottish Intercollegiate Guidelines Network (SIGN), and synthesized the evidence. Any disagreement among 2 review authors assigned for a task were resolved by discussion between the 2 reviewers; however, if consensus was not reached, a third author was called in for further discussion. In addition, any conflicts of interest with a reviewed manuscript concerning authorship were resolved by eliminating those authors and involvement of the review of the manuscripts.

\section{Outcome Measures}

The primary outcome was pain relief of $50 \%$ or more at various points in time.

The secondary outcomes included improvement of functional status, return to work, and reduction in opioid use.

\section{Methodological and Reporting Quality Assessment}

Risk of bias and methodological and reporting quality assessment was performed utilizing 3 tools: AMSTAR, PRISMA, and SIGN. In addition, risk of bias and quality assessment of RCTs was performed utilizing Cochrane review criteria (76), Interventional Pain Management techniques - Quality Appraisal of Reliability and Risk of Bias Assessment (IPM-QRB) criteria (77), and SIGN (78).

Correlations between the total scores of AMSTAR, PRISMA, and SIGN for systematic reviews and Cochrane review, IPM-QRB, were assessed for RCTs.

\section{Scoring AMSTAR}

Based on the previous publication (53) studying pain related articles, each AMSTAR item was rated as one point if the criterion is met or 0 points if the criterion is not met, unclear, or not applicable. Possible range for AMSTAR score for each systematic review was 0 to 11 . Systematic reviews were then classified as high 8 to 11 points, medium 4 to 7 points, or low methodologic quality 0 to 3 points as reported by multiple authors $(53,54)$. For compliance with individual AMSTAR items, cut-offs of $90 \%$ to $100 \%$ was utilized as high compliance, $70 \%$ to $89 \%$ as medium compliance, $30 \%$ to $69 \%$ as low compliance, and $0 \%$ to $29 \%$ as very low compliance.

\section{Scoring PRISMA}

The degree of compliance with PRISMA was assessed by scoring every item rated as yes for total compliance, unclear for partial compliance, or no for noncompliance, corresponding to the score values of $1,0.5$, or 0 respectively $(53,54)$. Possible range for PRISMA scores for each systematic review was 0 to 27 . To assess the compliance with individual PRISMA items, high compliance was utilized as $90 \%$ to $100 \%$, medium compliance as $70 \%$ to $89 \%$, low compliance as $30 \%$ to $69 \%$, and $0 \%$ to $29 \%$ as very low compliance.

\section{Scoring SIGN}

Methodologic quality assessment of systematic reviews was also conducted utilizing SIGN (78). Cho et al (33) utilizing SIGN in assessing treatment outcomes for patients with post lumbar surgery syndrome, which also included percutaneous adhesiolysis along with comparative analysis of spinal cord stimulation. The quality assessment was based on 3 options, i.e., those which were designated as ++ (indicated all or most of 
all standards are met), + (indicated some of the stand are met), and - (indicated all or most of all standards are not met).

\section{Scoring Cochrane Review Criteria}

Utilizing Cochrane review criteria, studies meeting the inclusion criteria with at least 9 of 13 criteria were considered high quality; 5 to 8 were considered moderate quality. Those meeting criteria of less than 5 were considered as low quality and were excluded.

\section{Scoring IPM-QRB Criteria}

Based on IPM-QRB criteria for randomized trials, the studies meeting the inclusion criteria, but scoring less than 16 were considered as low quality and were excluded; studies scoring from 16 to 31 were considered as moderate quality; and studies scoring from 32 to 48 were considered as high quality.

\section{Analysis of Evidence}

The analysis of evidence was based on best evidence synthesis for qualitative evidence (79) and the Systems to Rate the Strength of Scientific Evidence of the Agency for Healthcare and Quality (AHRQ) (80), as shown in Table 1 and 2.

In addition, recommendation grade was also utilized with classification from $A$ to $D$ based on the results of the evidence as shown in Table 3 (78).

\section{RESULTS}

Fig. 1 shows a flow diagram of the literature search and selection of 4 systematic reviews $(17,33,60,61)$ and 4 RCTs utilized in the systematic reviews $(63,64,66,68)$.

\section{Methodologic Quality of Systematic Reviews}

Methodologic quality of systematic reviews was

Table 1. Qualitative modified approach to grading of evidence.

\begin{tabular}{|c|c|l||}
\hline Level I & Strong & $\begin{array}{l}\text { Evidence obtained from multiple relevant high quality randomized controlled trials for } \\
\text { effectiveness }\end{array}$ \\
\hline Level II & Moderate & $\begin{array}{l}\text { Evidence obtained from at least one relevant high quality randomized controlled trial or multiple } \\
\text { relevant moderate or low quality randomized controlled trials }\end{array}$ \\
\hline Level III & Fair & $\begin{array}{l}\text { Evidence obtained from at least one relevant high quality nonrandomized trial or observational } \\
\text { study with multiple moderate or low quality observational studies }\end{array}$ \\
\hline Level IV & Limited & Evidence obtained from multiple moderate or low quality relevant observational studies \\
\hline Level V & Consensus based & $\begin{array}{l}\text { Opinion or consensus of large group of clinicians and/or scientists for effectiveness as well as to } \\
\text { assess preventive measures, adverse consequences, effectiveness of other measures. }\end{array}$ \\
\hline
\end{tabular}

Modified from: Manchikanti et al. A modified approach to grading of evidence. Pain Physician 2014; 17:E319-E325 (79).

Table 2. Degree of evidence as described by SIGN.

\begin{tabular}{|c|l|}
\hline $1++$ & $\begin{array}{l}\text { - High quality meta-analysis and systematic review conducted by randomized clinical trials } \\
\text { - Randomized controlled trials with a very low risk of bias }\end{array}$ \\
\hline $1+$ & $\begin{array}{l}\text { - Well-designed meta-analysis and systematic review conducted by randomized or non-randomized clinical trials } \\
\text { - Randomized or non-randomized clinical trials with a low risk of bias }\end{array}$ \\
\hline $1-$ & $\begin{array}{l}\text { - Meta analysis and systematic review conducted by randomized or non-randomized clinical trials } \\
\text { - Randomized or non-randomized clinical trials with a high risk of bias }\end{array}$ \\
\hline $2++$ & $\begin{array}{l}\text { - High-quality systematic review conducted by a patient control study, cohort study, or diagnosis analytic study } \\
\text { - High-quality patient control study, cohort study, or diagnosis analytic study of very low risk of confounding, bias or } \\
\text { contingency, or a high possibility of cause and effect relationship }\end{array}$ \\
\hline $2+$ & $\begin{array}{l}\text { - High-quality patient control study, cohort study, or diagnosis analytic study of the low risk of a confounding, bias or } \\
\text { contingency, or the normal possibility of a cause and effect relationship }\end{array}$ \\
\hline $2-$ & $\begin{array}{l}\text { - Patient control study, cohort study, or diagnosis analytic study of the high risk of a confounding bias or contingency, or the } \\
\text { low possibility of a cause and effect relationship }\end{array}$ \\
\hline 3 & - Non-analytic studies, e.g., before-and-after study, case series, case report \\
\hline 4 & - Expert opinion \\
\hline
\end{tabular}

Source: Harbour R, Miller J. A new system for grading recommendations in evidence based guidelines. BMJ 2001; 323:334-336 (78). 
Table 3. Recommendation grade.

\begin{tabular}{|l|l||}
\hline A & $\begin{array}{l}\text { - At least one metaanalysis, systematic review, or RCT rated as 1++ and directly applicable to the target population or } \\
\text { - A systematic review of RCTs or a body of evidence consisting principally of studies rated as 1 + directly applicable to the target } \\
\text { population and demonstrating overall consistency of results }\end{array}$ \\
\hline B & $\begin{array}{l}\text { - A body of evidence including studies rated as } 2++ \text { directly applicable to the target population and demonstrating overall consistency } \\
\text { of results or } \\
\text { - Extrapolated evidence from studies rated as } 1++ \text { or } 1+\end{array}$ \\
\hline C & $\begin{array}{l}\text { - A body of evidence including studies rated as } 2+\text { directly applicable to the target population and demonstrating overall consistency } \\
\text { of results or } \\
\text { - Extrapolated evidence from studies rated as } 2++\end{array}$ \\
\hline D & $\begin{array}{l}\text { - Evidence level } 3 \text { or } 4 \text { or } \\
\text { - Extrapolated evidence from studies rated as } 2+\end{array}$ \\
\hline
\end{tabular}

Source: Harbour R, Miller J. A new system for grading recommendations in evidence based guidelines. BMJ 2001; 323:334-336 (78).

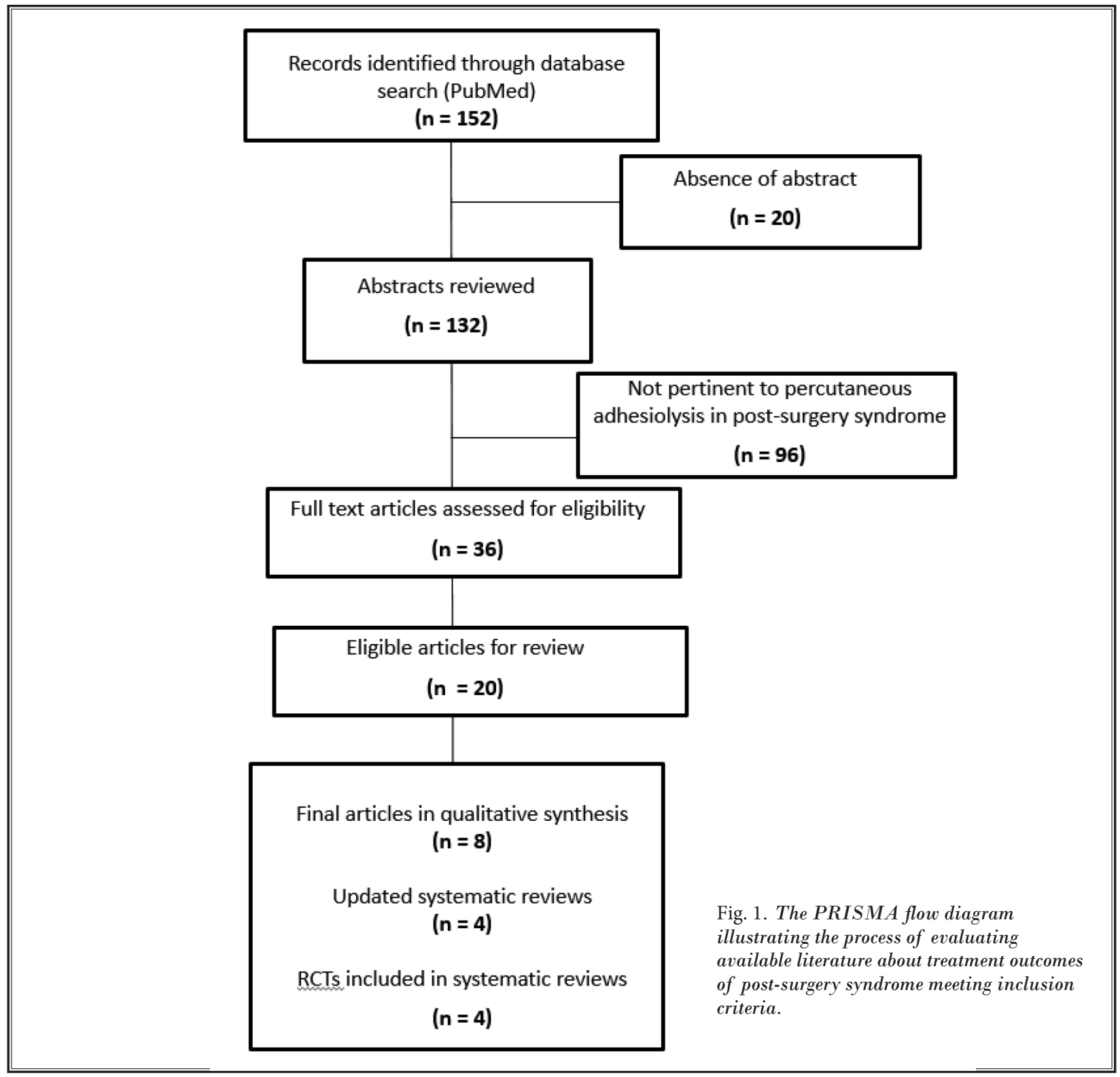


conducted utilizing PRISMA, AMSTAR, and SIGN checklists.

Compliance with PRISMA checklist is shown in Table 4. Based on the scoring principles, only one systematic review (17) met high compliance criteria with a score of 25 of 27,2 of the systematic reviews $(33,60)$ met medium compliance with scores of 22 and 23, whereas one systematic review (61) was of low compliance rate with compliance of 16 .

AMSTAR scoring is shown in Table 5. Based on this

Table 4. Compliance with PRISMA checklist.

\begin{tabular}{|c|c|c|c|c|}
\hline PRISMA Item & $\begin{array}{c}\text { Helm et } \\
\text { al (17) }\end{array}$ & $\begin{array}{c}\text { Manchikanti } \\
\text { et al (60) }\end{array}$ & $\begin{array}{l}\text { Cho et } \\
\text { al (33) }\end{array}$ & $\begin{array}{c}\text { Brito-García } \\
\text { et al (61) }\end{array}$ \\
\hline \multicolumn{5}{|l|}{ TITLE } \\
\hline 1. Systematic review, meta-analysis, or both in the title? & 1 & 1 & 1 & 1 \\
\hline \multicolumn{5}{|l|}{ ABSTRACT } \\
\hline 2. Structured summary in the abstract? & 1 & 1 & 1 & 1 \\
\hline \multicolumn{5}{|l|}{ INTRODUCTION } \\
\hline 3. Rationale for review in the introduction? & 1 & 1 & 1 & 0 \\
\hline 4. Objectives statement in the introduction? & 1 & 1 & 1 & 1 \\
\hline \multicolumn{5}{|l|}{ METHODS } \\
\hline 5. Protocol registration information provided? & 0 & 0 & 0 & 1 \\
\hline 6. Methods for eligibility criteria included? & 1 & 1 & 1 & 1 \\
\hline 7. Information sources in the methods? & 1 & 1 & 1 & 0 \\
\hline 8. Full search strategy provided? & 1 & 1 & 1 & 1 \\
\hline 9. Process of study selection provided? & 1 & 1 & 1 & 0 \\
\hline 10. Process of data extraction provided? & 1 & 1 & 1 & 0 \\
\hline 11. List and define all variables for which data were sought? & 1 & 1 & 1 & 0 \\
\hline 12. Methods for risk of bias in individual studies provided? & 1 & 1 & 1 & 1 \\
\hline 13. Methods for principal study measures provided? & 1 & 1 & 1 & 1 \\
\hline 14. Methods for synthesis of results provided? & 1 & 1 & 1 & 0 \\
\hline 15. Methods for risk of bias across studies provided (publication bias)? & 1 & 1 & 1 & 0 \\
\hline 16. Methods of additional analyses provided? & 1 & 0 & 1 & 0 \\
\hline \multicolumn{5}{|l|}{ RESULTS } \\
\hline 17. Description of studies included/excluded? & 1 & 1 & 1 & 1 \\
\hline 18. Study characteristics for the included studies provided? & 1 & 1 & 1 & 1 \\
\hline 19. Risk of bias in individual studies assessed? & 1 & 1 & 1 & 1 \\
\hline 20. Results of the individual studies presented ideally in a forest plot? & 1 & 1 & 1 & 1 \\
\hline 21. Clear synthesis of the results with proper measurements in consistency? & 1 & 0 & 0 & 0 \\
\hline 22. Risk of bias across individual studies assessed (publication bias)? & 0 & 0 & 0 & 0 \\
\hline 23. Results of any additional analyses provided? & 1 & 0 & 0 & 0 \\
\hline \multicolumn{5}{|l|}{ DISCUSSION } \\
\hline 24. Summary of evidence in the discussion? & 1 & 1 & 1 & 1 \\
\hline 25. Discussion of limitations of the study? & 1 & 1 & 1 & 1 \\
\hline 26. Discussion of the implications and future research? & 1 & 1 & 1 & 1 \\
\hline \multicolumn{5}{|l|}{ FUNDING } \\
\hline 27. Funding source and roles of the authors provided? & 1 & 1 & 1 & 1 \\
\hline TOTAL & 25 & 22 & 23 & 16 \\
\hline
\end{tabular}

Source: Moher D, Liberati A, Tetzlaff J, Altman DG; PRISMA Group. Preferred reporting items for systematic reviews and meta-analyses: the PRISMA statement. Ann Intern Med 2009; 151:264-269, W64 (3). 
Effectiveness of Percutaneous Adhesiolysis in Post Lumbar Surgery Syndrome

Table 5. Compliance with individual AMSTAR checklist items of systematic reviews.

\begin{tabular}{|c|c|c|c|c|}
\hline & $\begin{array}{l}\text { Helm et } \\
\text { al (17) }\end{array}$ & $\begin{array}{c}\text { Manchikanti } \\
\text { et al (60) }\end{array}$ & $\begin{array}{c}\text { Cho et al } \\
(33)\end{array}$ & $\begin{array}{l}\text { Brito-García } \\
\text { et al (61) }\end{array}$ \\
\hline 1. Was a priori design provided (protocol established before the conduct of review)? & 1 & 1 & 1 & 1 \\
\hline 2. Was there duplicate study selection and data extraction? & 1 & 1 & 1 & 1 \\
\hline 3. Was a comprehensive literature search performed? & 1 & 1 & 1 & 0 \\
\hline 4. Was the status of publication (ie, gray literature) used as an inclusion criterion? & 0 & 0 & 0 & 0 \\
\hline 5. Was a list of studies (included and excluded) provided? & 1 & 1 & 1 & 0 \\
\hline 6. Were the characteristics of the included studies provided? & 1 & 1 & 1 & 1 \\
\hline 7. Was the scientific quality of the included studies assessed and documented? & 1 & 1 & 1 & 1 \\
\hline $\begin{array}{l}\text { 8. Was the scientific quality of the included studies used appropriately in } \\
\text { formulating conclusions? }\end{array}$ & 1 & 1 & 1 & 0 \\
\hline 9. Were the methods used to combine the findings of studies appropriate? & 1 & 1 & 1 & 0 \\
\hline 10. Was the likelihood of publication bias assessed? & 1 & 1 & 1 & 0 \\
\hline $\begin{array}{l}\text { 11. Was the conflict of interest included, both for the systematic review authors } \\
\text { and included studies' authors? }\end{array}$ & 1 & 1 & 1 & 0 \\
\hline TOTAL & 10 & 10 & 10 & 4 \\
\hline
\end{tabular}

Y=Yes; N=No; NA=Not applicable

Source: A Measurement Tool to Assess Systematic Reviews (AMSTAR). https://amstar.ca/ (59)

scoring, 3 systematic reviews $(17,33,60)$ were shown to be of high quality with $90 \%$ compliance, whereas one systematic review (61) was shown to be of low compliance.

SIGN scoring is shown in Table 6 . This showed high quality review for 3 of the 4 systematic reviews $(17,33,60)$, whereas one systematic review (61) was of low quality or unacceptable. Finally, it was utilized as low quality rather than rejected, based on the consensus.

Table 7 summarizes the compliance with AMSTAR, PRISMA, and SIGN checklists for systematic reviews. Only one systematic review was rated with high compliance with all 3 checklists (17). Two systematic reviews $(33,60)$ rated high with AMSTAR and SIGN; however, medium with PRISMA. The final systematic review (61) rated low quality with AMSTAR, PRISMA, and SIGN checklists.

\section{Methodologic Quality Assessment of RCTs}

Risk of bias and methodologic quality assessment of RCTs in 4 published systematic reviews is shown in Table 8 . Three of the 4 studies consistently were rated as high quality $(63,64,69)$, whereas, one study was rated as moderate quality (66).

Two systematic reviews $(33,61)$ included 2 RCTs $(63,64)$, one of them $(60)$ included 3 RCTs $(63,64,66)$ and one included 4 RCTs $(63,64,66,69)$. Table 8 shows methodologic quality assessment utilizing Cochrane
Review criteria, SIGN checklist, or IPM-QRB checklist. Methodologic quality was rated as high for Chun-Jing et al (63) in 2 of the 4 reviews; whereas in one systematic review (33), a trial was not included and in another systematic review it was rated as moderate quality with Cochrane Review criteria by Brito-García et al (61). Manchikanti et al's RCT (64) utilized in all 4 systematic reviews was shown to be of high quality in 3 systematic reviews $(17,33,60)$ and low quality in one systematic review. Two other RCTs $(66,69)$ were analyzed only in 2 systematic reviews $(17,33)$ showing high quality with Cochrane Review criteria, as well as IPM-QRB.

\section{Study Characteristics}

Study characteristics of 4 RCTs are shown in Table 9.

\section{Synthesis and Analysis of Evidence}

As shown in Table 10, the evidence is Level I based on best evidence synthesis and Grade A, based on grading recommendations (78).

\section{Discussion}

The results of the present research demonstrate that of the 4 current systematic reviews, 3 were performed appropriately and one was performed inappropriately providing low methodologic quality assessment and inappropriate conclusions. Based on the analysis from the 4 systematic reviews and 4 RCTs included in the system- 
Table 6. SIGN checklist for systematic reviews.

\begin{tabular}{|c|c|c|c|c|c|c|c|}
\hline Secti & $\begin{array}{l}\text { n I: INTERNAL VALIDITY } \\
\text { In a well conducted systematic review }\end{array}$ & \multicolumn{2}{|c|}{ Does this study do it? } & \multirow{2}{*}{$\begin{array}{l}\text { Helm et } \\
\text { al (17) } \\
\text { Y }\end{array}$} & \multirow{2}{*}{$\begin{array}{l}\text { Manchikanti } \\
\text { et al (60) } \\
\text { Y }\end{array}$} & \multirow{2}{*}{$\begin{array}{l}\begin{array}{l}\text { Cho et } \\
\text { al (33) }\end{array} \\
\text { Y }\end{array}$} & \multirow{2}{*}{$\begin{array}{l}\begin{array}{l}\text { Brito- } \\
\text { García et }\end{array} \\
\text { al (61) } \\
\mathrm{N}\end{array}$} \\
\hline 1.1 & $\begin{array}{l}\text { The research question is clearly defined and the } \\
\text { inclusion/ exclusion criteria must be listed in the } \\
\text { paper. If no, reject }\end{array}$ & Yes $\square$ & No $\square$ & & & & \\
\hline \multirow{2}{*}{1.2} & \multirow{2}{*}{$\begin{array}{l}\text { A comprehensive literature search is carried out. } \\
\text { If no, reject }\end{array}$} & Yes $\square$ & No $\square$ & \multirow{2}{*}{$\mathrm{Y}$} & \multirow{2}{*}{$\mathrm{Y}$} & \multirow{2}{*}{$\mathrm{Y}$} & \multirow{2}{*}{$\mathrm{N}$} \\
\hline & & \multicolumn{2}{|c|}{ Not applicable $\square$} & & & & \\
\hline \multirow{2}{*}{1.3} & \multirow{2}{*}{ At least two people should have selected studies. } & \multirow{2}{*}{ Yes $\square$} & No $\square$ & \multirow{2}{*}{$\mathrm{Y}$} & \multirow{2}{*}{$\mathrm{Y}$} & \multirow{2}{*}{$\mathrm{Y}$} & \multirow{2}{*}{ Y } \\
\hline & & & Can’t say $\square$ & & & & \\
\hline \multirow{2}{*}{1.4} & \multirow{2}{*}{ At least two people should have extracted data. } & \multirow{2}{*}{ Yes $\square$} & No $\square$ & \multirow{2}{*}{$\mathrm{Y}$} & \multirow{2}{*}{$\mathrm{Y}$} & \multirow{2}{*}{$\mathrm{Y}$} & \multirow{2}{*}{$\mathrm{Y}$} \\
\hline & & & Can’t say $\square$ & & & & \\
\hline 1.5 & $\begin{array}{l}\text { The status of publication was not used as an } \\
\text { inclusion criterion. }\end{array}$ & Yes $\square$ & No $\square$ & Y & $\mathrm{Y}$ & $\mathrm{Y}$ & Y \\
\hline 1.6 & The excluded studies are listed. & Yes $\square$ & No $\square$ & $\mathrm{Y}$ & $\mathrm{Y}$ & $\mathrm{N}$ & $\mathrm{N}$ \\
\hline 1.7 & $\begin{array}{l}\text { The relevant characteristics of the included studies } \\
\text { are provided. }\end{array}$ & Yes $\square$ & No $\square$ & Y & $\mathrm{Y}$ & $\mathrm{Y}$ & $\mathrm{Y}$ \\
\hline 1.8 & $\begin{array}{l}\text { The scientific quality of the included studies was } \\
\text { assessed and reported. }\end{array}$ & Yes $\square$ & No $\square$ & Y & Y & $\mathrm{Y}$ & $\mathrm{Y}$ \\
\hline 1.9 & $\begin{array}{l}\text { Was the scientific quality of the included studies } \\
\text { used appropriately? }\end{array}$ & Yes $\square$ & No $\square$ & Y & Y & $\mathrm{Y}$ & $\mathrm{N}$ \\
\hline \multirow[b]{2}{*}{1.10} & \multirow{2}{*}{$\begin{array}{l}\text { Appropriate methods are used to combine the } \\
\text { individual study findings. }\end{array}$} & \multirow[b]{2}{*}{ Yes $\square$} & No $\square$ & \multirow[b]{2}{*}{ NA } & \multirow[b]{2}{*}{ NA } & \multirow[b]{2}{*}{ NA } & \\
\hline & & & $\begin{array}{l}\text { Not } \\
\text { applicable } \square\end{array}$ & & & & NA \\
\hline & & Yes $\square$ & & & & & \\
\hline 1.11 & $\begin{array}{l}\text { appropriately. } \\
\text { and }\end{array}$ & $\begin{array}{l}\text { Not } \\
\text { applicable } \square\end{array}$ & No $\square$ & $\mathrm{Y}$ & $\mathrm{Y}$ & $\mathrm{Y}$ & $\mathrm{N}$ \\
\hline 1.12 & Conflicts of interest are declared. & Yes $\square$ & No $\square$ & $\mathrm{Y}$ & $\mathrm{Y}$ & $\mathrm{Y}$ & $\mathrm{Y}$ \\
\hline Secti & n 2: OVERALL ASSESSMENT OF THE STUDY & & & & & & \\
\hline & & High quality & $++) \square$ & & & & \\
\hline 2.1 & What is your overall assessment of the & Acceptable $(+$ & & & & & \\
\hline 2.1 & methodological quality of this review? & Low quality ( & & ++ & ++ & ++ & - \\
\hline & & Unacceptable & - reject $0 \square$ & & & & \\
\hline 2.2 & $\begin{array}{l}\text { Are the results of this study directly applicable to } \\
\text { the patient group targeted by this guideline? }\end{array}$ & Yes $\square$ & & $\mathrm{Y}$ & Y & $\mathrm{Y}$ & $\mathrm{N}$ \\
\hline
\end{tabular}

Table 7. Compliance with AMSTAR, PRISMA, and SIGN checklists for systematic reviews.

\begin{tabular}{|l|c|c|c|}
\hline \multicolumn{1}{|c|}{ Systematic Reviews } & AMSTAR (0-11) & PRISMA (0-27) & SIGN \\
\hline Helm et al (17) & High - 10 & High - 25 & ++ \\
\hline Manchikanti et al (60) & High - 10 & Medium - 22 & ++ \\
\hline Cho et al (33) & High - 10 & Medium - 23 & ++ \\
\hline Brito-García et al (61) & Low - 4 & Low - 16 & - \\
\hline
\end{tabular}


Effectiveness of Percutaneous Adhesiolysis in Post Lumbar Surgery Syndrome

Table 8. Methodologic quality assessment utilizing Cochrane Review criteria or SIGN checklist or IPM-QRB.

\begin{tabular}{|c|c|c|c|c|c|c|}
\hline & \multicolumn{2}{|c|}{ Helm et al (17) } & \multirow{2}{*}{$\begin{array}{c}\text { Cho et al (33) } \\
\text { SIGN }\end{array}$} & \multicolumn{2}{|c|}{ Manchikanti et al (60) } & \multirow{2}{*}{$\begin{array}{c}\begin{array}{c}\text { Brito-García et } \\
\text { al (61) }\end{array} \\
\text { Cochrane }\end{array}$} \\
\hline & Cochrane & IPM-QRB & & Cochrane & IPM-QRB & \\
\hline Chun-Jing et al (63) & $12 / 13$ & $34 / 48$ & $1++$ & N/A & N/A & $6 / 11$ \\
\hline Manchikanti et al (64) & $12 / 13$ & $42 / 48$ & $1++$ & $9 / 12$ & $41 / 42$ & $4 / 11$ \\
\hline Heavner et al (66) & $10 / 13$ & $23 / 48$ & N/A & $9 / 12$ & $37 / 42$ & N/A \\
\hline Manchikanti et al (69) & $12 / 13$ & $37 / 48$ & N/A & $9 / 12$ & $40 / 42$ & N/A \\
\hline
\end{tabular}

atic reviews, the present study showed Level I evidence for percutaneous adhesiolysis in managing post lumbar surgery syndrome patients with recalcitrant pain and disability after failure of fluoroscopically directed epidural injections. Post spinal surgery syndrome or post lumbar surgery syndrome is often conflated with failed back surgery syndrome, which is considered as a misnomer and derogatory for surgical specialties $(33,81)$. Post lumbar surgery syndrome nonresponsive to epidural injections or other treatments correcting available pathology are commonly treated with percutaneous adhesiolysis or spinal cord stimulation. Cho et al (33) in a systematic review described and showed significant evidence for both percutaneous adhesiolysis and spinal cord stimulation with a recommendation of Level A for epidural adhesiolysis for 6 to 24 months of pain relief and functional improvement and Level B for spinal cord stimulation.

Among these systematic reviews, Helm et al (17) performed an appropriate methodologic quality assessment of RCTs utilizing Cochrane review criteria (76) and IPM-QRB criteria (77). They found Level I or strong evidence for the efficacy of percutaneous adhesiolysis in the treatment of chronic refractory low back and lower extremity pain of various origins. Level I was defined as evidence obtained from multiple relevant, high quality RCTs based on qualitative modified approach on grading of evidence (79). In reference to RCTs, utilizing Cochrane review criteria, all the manuscripts were rated as high quality, and IPM-QRB criteria, one manuscript was rated as moderate quality, while all 3 manuscripts $(63,64,69)$ referring to post laminectomy syndrome were rated as high quality. Helm et al (17) also performed meta-analysis showing significant improvement related to percutaneous adhesiolysis contributing to Level I results.

Manchikanti et al (60) evaluated the effectiveness of percutaneous adhesiolysis in the treatment of post lumbar surgery syndrome with inclusion of 4 RCTs, of which 3 of the 4 were rated as high quality based on
Cochrane review criteria as well as IPM-QRB $(76,77)$. Utilizing grading and synthesis of best evidence by qualitative analysis, they concluded that evidence was Level II based on best evidence synthesis. The authors have not performed meta-analysis due to variability among the studies.

Cho et al (33) in 2017 published the results of treatment outcomes for patients with failed back surgery in a systematic review. In this assessment, they have analyzed spinal cord stimulation, percutaneous adhesiolysis, and caudal epidural injections. With identification of 6 RCTs to include all techniques and 4 systematic reviews, they utilized various types of criteria for judgement of quality assessment, degree of evidence, and recommendation grading. They utilized ++ as highest for criteria for judgement of quality assessment, 1++ for degree of evidence, and A for recommendation grade. They also utilized SIGN checklist for RCTs and for systematic reviews for methodologic quality assessment (78). These authors have provided a high level of methodologic quality for RCTs $(63,64)$. Internal validity of percutaneous adhesiolysis was similar or even superior to the RCTs and systematic reviews of spinal cord stimulation (11,70-72). Based on this analysis, they showed that epidural adhesiolysis showed Grade A evidence for 6-24 months.

In contrast to these 3 systematic reviews published since 2015, a 2018 publication by a nonphysician primary author and none of the authors practicing in this procedure assessed efficacy, effectiveness, safety, and cost effectiveness of epidural adhesiolysis for treating failed back surgery syndrome in a systematic review without meta-analysis (61). They provided erroneous methodologic quality assessment rating the trials with downgrading to low quality, which have been rated as of high quality by Cochrane review (76), IPM-QRB (77), and SIGN (78). They considered them as high risk of bias utilizing only 2 studies for efficacy or effectiveness by Manchikanti et al (64) and Chun-Jing et al (63).

In recent years, significant controversy has been 
Pain Physician: July/August 2019: 22:307-322




Table 10. Articles for synthetic analysis showing the effectiveness of epidural adhesiolysis for FBSS.

\begin{tabular}{|c|c|c|c|c|c|}
\hline Authors & Type & $\begin{array}{l}\text { Intervention and } \\
\text { control }\end{array}$ & $\begin{array}{l}\text { F/U period } \\
\text { (mos.) }\end{array}$ & Conclusion & Methodologic Quality \\
\hline Chun-Jing et al (63) & RCT & $\begin{array}{l}\text { EA }(\mathrm{N}=46) \\
\text { ESI }(\mathrm{N}=46)\end{array}$ & 6 & $\begin{array}{l}\text { Patients on epidural lysis reported that } \\
\text { the clinical effectiveness rate was } 50 \% \text {. For } \\
\text { control patients it was } 5.26 \% \text {, and there was a } \\
\text { statistical difference between the } 2 \text { groups. }\end{array}$ & $\begin{array}{l}\text { Cochrane } \\
11 / 12 \\
\text { IPM-QRB } \\
34 / 48\end{array}$ \\
\hline Manchikanti et al (64) & RCT & $\begin{array}{l}\text { EA }(\mathrm{N}=60) \\
\text { ESI }(\mathrm{N}=60)\end{array}$ & 24 & $\begin{array}{l}\text { Significant pain relief and functional } \\
\text { improvement were recorded in } 73 \% \text { and } 82 \% \\
\text { of the patients in the EA group versus } 12 \% \\
\text { and } 5 \% \text { in the ESI group at the } 1 \text { - and } 2 \text {-year } \\
\text { follow-up }(\mathrm{P}<0.001) \text {. }\end{array}$ & $\begin{array}{l}\text { Cochrane } \\
11 / 12 \\
\text { IPM-QRB } \\
34 / 48\end{array}$ \\
\hline Heavner et al (66) & RCT & $\begin{array}{l}83 \text { patients in } 4 \\
\text { groups }\end{array}$ & $3,6,12$ months & $\begin{array}{l}\text { Moderate quality study comparing } 4 \\
\text { treatment options. Reduced additional } \\
\text { procedures }\end{array}$ & $\begin{array}{l}\text { IPM-QRB } \\
23 / 48\end{array}$ \\
\hline Manchikanti et al (69) & RCT & 75 & $3,6,12$ months & $\begin{array}{l}\text { High quality RCT showing that adhesiolysis } \\
\text { provides significant relief regardless of } \\
\text { whether normal saline or hypertonic saline } \\
\text { is used. }\end{array}$ & $\begin{array}{l}\text { Cochrane } \\
11 / 12 \\
\text { IPM-QRB } \\
37 / 48 \\
\end{array}$ \\
\hline Helm et al (17) & SR & NA & NA & $\begin{array}{l}\text { Applying the USPSTF criteria, there is } \\
\text { reasonable evidence that percutaneous } \\
\text { adhesiolysis is effective in relieving low back } \\
\text { and/or leg pain caused by FBSS. }\end{array}$ & $\begin{array}{l}\text { AMSTAR } \\
10 / 11 \\
\text { PRISMA } \\
25 / 27 \\
\text { SIGN ++ } \\
\end{array}$ \\
\hline Manchikanti et al (60) & SR & NA & NA & $\begin{array}{l}\text { Applying the USPSTF criteria, there is } \\
\text { reasonable evidence that percutaneous } \\
\text { adhesiolysis is effective in relieving low back } \\
\text { and/or leg pain caused by FBSS. }\end{array}$ & $\begin{array}{l}\text { AMSTAR } \\
10 / 11 \\
\text { PRISMA } \\
22 / 27 \\
\text { SIGN } 1++\end{array}$ \\
\hline Cho et al (33) & SR & NA & NA & $\begin{array}{l}\text { Applying AHRQ criteria. Authors have } \\
\text { presented percutaneous adhesiolysis } 1++ \\
\text { evidence, whereas spinal cord stimulation } \\
\text { was 1++ with Grade A recommendation, } \\
\text { compared to spinal cord stimulation of Grade } \\
\text { B recommendation. }\end{array}$ & $\begin{array}{l}\text { AMSTAR } \\
10 / 11 \\
\text { PRISMA } \\
23 / 25 \\
\text { SIGN } 1++\end{array}$ \\
\hline Brito-García et al (61) & SR & NA & NA & $\begin{array}{l}\text { Applying deeply flawed methodology with } \\
\text { lack of understanding of the procedure, } \\
\text { misrepresentation of the evidence leading } \\
\text { to erroneous conclusions. Authors have } \\
\text { concluded that the evidence of the efficacy } \\
\text { and cost effectiveness of adhesiolysis for } \\
\text { treating FBSS was nonexistent. }\end{array}$ & $\begin{array}{l}\text { AMSTAR } \\
4 / 11 \\
\text { PRISMA } \\
16 / 27 \\
\text { SIGN - }\end{array}$ \\
\hline
\end{tabular}

developed in performing RCTs, as well as synthesizing the evidence with systematic reviews and meta-analysis. Clark et al (20) filed a complaint with the chief editor of Cochrane reviews and published articles regarding inaccurate reporting, misreporting, inability to identify all the available studies, and undisclosed conflicts of interest. Similar reports have been found for interventional pain management over the years with biased assessment, not only for percutaneous adhesiolysis and vertebroplasty, but for epidural injections, facet joint interventions, and other treatments and cost effective utility analysis (82-86).

While 3 systematic reviews performed were of high quality and one was of low quality by Brito-García et al (61), this systematic review failed to follow principles of EBM and lacked clinical experience and understanding of the procedure. Authors of this systematic review (61) raised a multitude of questions in reference to the RCT by Manchikanti et al (64), in reference to allocation concealment and blinding, in addition to other 
misconceptions. However, the manuscript described the allocation concealment clearly along with blinding for the intervention. Of course, double-blinding is difficult for the performing physician; however, blinding was maintained by multiple means by separating the physician performing the procedure and the one assessing the results, and also mixing the study patients with other patients receiving routine treatment. Even then, the authors (64) have provided information that blinding was considered inadequate in patients in Group I as the physician performing the procedure was informed of Group I as it was necessary to position the catheter at S3, which was not a usual practice. However, the drugs injected during the usual procedure were not injected in the operating room, and the group assignment was not revealed to other staff members or the outcome assessor.

Brito-Garcia et al (61) have described that the dropout rate was not acceptable. Dropout rate was described and acceptability is a subjective matter. The dropout rate in the treatment group was only $3 \%$ at the end of one year and $10 \%$ at the end of 2 years. The authors (61) also criticized similarity in groups at baseline as the most important prognostic indicator. However, there were no differences between the groups for any of the indicators, specifically the most important indicators which are pain distribution, pain ratio, and surgical history. They (61) were also unclear about cointerventions, if they were avoided or comparable. Cointerventions were clearly described in the manuscript, which were similar in both groups (64). All of them also continued previously directed therapeutic exercise programs, as well as their work, if they were working, which is succinctly described as other parameters (64).

In reference to the compliance and its acceptability in all groups, the compliance was overwhelmingly acceptable in Group II, whereas in Group I, patients withdrew because of the continued pain (64), even though Brito-Garcia et al (61) appears to misunderstand several basic elements of the study.

Further criticism also included that criteria for repeating epidural injections were not disclosed (61), which is disappointing. The succinct description shows that adhesiolysis was repeated after 3 or more months if the degree of improvement in disability or pain relief experienced after the first procedure deteriorated to $\geq 50 \%$ as described in the manuscript itself. Further, they also described losses of $87 \%$ in the caudal epidural group, which was the control group after they have failed the epidural injections at 2 years rather than one year (64). At one year, it was more reasonable with $62 \%$ dropout in the control group, whereas it was less than $20 \%$ at 6 months.

Brito-Garcia et al (61) also criticized that patients could have undergone epidural injections before entering the trial, so it is unclear whether they were blinded to the treatment they received. A more robust review of the inclusion criteria would have demonstrated that all patients had previously failed epidural injections; however, without catheterization (64). The authors (61) also stated patients could be informed of the treatment they had been assigned to if they asked about it. This is not described anywhere in the manuscript. Patients were informed of the treatment only at the time of unblinding. They stated that groups were not similar at baseline in important variables, e.g., opioid use; however, they have not described any other aspects and it is unclear where these thoughts came from as they were not discussed in the analysis or the manuscript.

Brito-Garcia et al (61) also missed the fact that cost effectiveness studies have already been published (82). Further, they attempted to evaluate safety from RCTs and small observational studies, which is problematic for the reasons described above.

Similar criticism was provided about Chun-Jing et al's (63) manuscript.

They (61) also excluded 2 manuscripts by Heavner et al (66) and Manchikanti et al (69), which included an overwhelming proportion of post lumbar laminectomy patients. The present systematic review of systematic reviews and analysis of RCTs included in these systematic reviews succinctly demonstrates the value of EBM and at the same time shows the consequences of inappropriate analysis.

\section{Conclusion}

This systematic review of 4 systematic reviews which included 4 RCTs, succinctly demonstrates the value of performing appropriate risk of bias and quality assessment of RCTs and subsequent analysis of systematic reviews. Moreover, the present study demonstrates significant evidence when the systematic review is performed appropriately, without bias, knowledge of methodology, and with an understanding of clinical activity. Overall, the present analysis shows Level I evidence for percutaneous adhesiolysis, based on evidence from 4 published RCTs and 3 of the 4 systematic reviews. 


\section{Author Affiliations}

Dr. Manchikanti is Co-Director, Pain Management Centers of America, Paducah, KY and Evansville, IN, Clinical Professor, Anesthesiology and Perioperative Medicine, University of Louisville, Louisville, KY, and Professor of Anesthesiology-Research, Department of Anesthesiology, School of Medicine, LSU Health Sciences Center, New Orleans, LA. drlm@thepainmd.com

Dr. Soin is Medical Director, Ohio Pain Clinic, Centerville, $\mathrm{OH}$, Clinical Assistant Professor of Surgery at Wright State University, Dayton, $\mathrm{OH}$, Assistant Professor, Ohio University College of Medicine, Athens, $\mathrm{OH}$, and, Clinical Professor of Pain Management and Anesthesiology, University of Pikeville, Pikeville, KY ohiopainclinic@gmail.com

Dr. Boswell is Professor and Program Director, Pain
Medicine, Department of Anesthesiology, University of Toledo College of Medicine and Life Sciences, Toledo, OH mark.boswell2@utoledo.edu

mvboswell01@gmail.com

Dr. Kaye is Professor, Program Director, and Chairman, Department of Anesthesiology, Louisiana State University Health Science Center, New Orleans, LA. akaye@Isuhsc.edu; alankaye44@hotmail.com

Dr. Sanapati is Co-Director, Pain Management Centers of America, Evansville, IN msanapati@gmail.com

Dr. Hirsch is Vice Chair and Service Line Chief of Neurointerventional Radiology, Chief of Neurointerventional Spine, Massachusetts General Hospital and Harvard Medical School, Boston, MA hirsch@snisonline. org

\section{REFERENCES}

1. Manchikanti L, Benyamin RM, Helm II S, Hirsch JA. Evidence-based medicine, systematic reviews, and guidelines in interventional pain management: Part 3. Systematic reviews and meta-analyses of randomized trials. Pain Physician 2009; 12:35-72.

2. Nguyen NH, Singh S. A Primer on systematic reviews and meta-analyses. Semin Liver Dis 2018; 38:103-111.

3. Moher D, Liberati A, Tetzlaff J, Altman DG; PRISMA Group. Preferred reporting items for systematic reviews and meta-analyses: the PRISMA statement. Ann Intern Med 2009; 151:264-269, W64.

4. Hirsch JA, Schaefer PW, Romero JM, Rabinov JD, Sanelli PC, Manchikanti L. Comparative effectiveness research. AJNR Am J Neuroradiol 2014; 35:1677-1680.

5. Chou R, Hashimoto R, Friedly J, Fu R, Bougatsos C, Dana T, Sullivan SD, Jarvik J. Epidural corticosteroid injections for radiculopathy and spinal stenosis: A systematic review and meta-analysis. Ann Intern Med 2015; 163:373-381.

6. Manchikanti L, Knezevic NN, Boswell MV, Kaye AD, Hirsch JA. Epidural injections for lumbar radiculopathy and spinal stenosis: A comparative systematic review and meta-analysis. Pain Physician 2016; 19:E365-E410.

7. Boswell MV, Manchikanti L. Appropriate design and methodologic quality assessment, clinically relevant outcomes are essential to determine the role of epidural corticosteroid injections. Com- mentary RE: Chou R, Hashimoto R, Friedly J, Fu R, Bougatsos C, Dana T, Sullivan SD, Jarvik J. Epidural corticosteroid injections for radiculopathy and spinal stenosis: A systematic review and metaanalysis. Ann Intern Med 2015; 163:373381. Evid Based Med 2016; 21:89.

8. Manchikanti L, Benyamin RM, Falco FJ, Kaye AD, Hirsch JA. Do epidural injections provide short- and long-term relief for lumbar disc herniation? A systematic review. Clin Orthop Relat Res 2015; 473:1940-1956.

9. Manchikanti L, Nampiaparampil DE, Manchikanti KN, Falco FJE, Singh V, Benyamin RM, Kaye AD, Sehgal N, Soin A, Simopoulos TT, Bakshi S, Gharibo CG, Gilligan CJ, Hirsch JA. Comparison of the efficacy of saline, local anesthetics, and steroids in epidural and facet joint injections for the management of spinal pain: A systematic review of randomized controlled trials. Surg Neurol Int 2015; 6:S194-S235.

10. Helm $S$ 2nd, Simopoulos TT, Stojanovic MP, Abdi S, El Terany MA. Effectiveness of thermal annular procedures in treating discogenic low back pain. Pain Physician 2017; 20:447-470.

11. Grider JS, Manchikanti L, Carayannopoulos A, Sharma ML, Balog CC, Harned ME, Grami V, Justiz R, Nouri KH, Hayek SM, Vallejo R, Christo PJ. Effectiveness of spinal cord stimulation in chronic spinal pain: A systematic review. Pain Physician 2016; 19: E33-E54.

12. Simopoulos TT, Manchikanti L, Gupta S, Aydin SM, Kim CH, Solanki D, Nampia- parampil DE, Singh V, Staats PS, Hirsch JA. Systematic review of the diagnostic accuracy and therapeutic effectiveness of sacroiliac joint interventions. Pain Physician 2015; 18:E713-E756.

13. Manchikanti L, Hirsch JA, Falco FJE, Boswell MF. Management of lumbar zygapophysial (facet) joint pain. World J Orthop 2016; 7:315-337.

14. Lee JH, Kim DH, Kim DH, Shin $\mathrm{KH}$, Park SJ, Lee GJ, Lee CH, Yang HS. Comparison of clinical efficacy of epidural injection with or without steroid in lumbosacral disc herniation: A systematic review and meta-analysis. Pain Physician 2018; 21:449-468.

15. Lee JH, Shin KH, Park SJ, Lee GJ, Lee $\mathrm{CH}$, Kim DH, Kim DH, Yang HS. Comparison of clinical efficacy between transforaminal and interlaminar epidural injections in lumbosacral disc herniation: A systematic review and metaanalysis. Pain Physician 2018; 21:433-448.

16. Ioannidis JPA. The mass production of redundant, misleading, and conflicted systematic reviews and meta-analyses. Milbank Q 2016; 94:485-514.

17. Helm II S, Racz GB, Gerdesmeyer L, Justiz L, Hayek SM, Kaplan ED, El Terany MA, Knezevic NN. Percutaneous and endoscopic adhesiolysis in managing low back and lower extremity pain: A systematic review and meta-analysis. Pain Physician 2016; 19:E245-E281.

18. Beall DP, Tutton SM, Murphy K, Olan W, Warner CB, Test JB. Analysis of reporting bias in vertebral augmentation. Pain Physician 2017; 20:E1081-E1090. 
19. Zhang H, Xu C, Zhang T, Gao Z, Zhang T. Does percutaneous vertebroplasty or balloon kyphoplasty for osteoporotic vertebral compression fractures increase the incidence of new vertebral fractures? A meta-analysis. Pain Physician 2017; 20:E13-E28.

20. Clark W, Bird P, Diamond T, Gonski P, Gebski V. Cochrane vertebroplasty review misrepresented evidence for vertebroplasty with early intervention in severely affected patients. BM] Evid Based Med 2019 Mar 9. [Epub ahead of print]

21. Manchikanti L, Sanapati J, Benyamin RM, Atluri S, Kaye AD, Hirsch JA. Reframing the prevention strategies of the opioid crisis: Focusing on prescription opioids, fentanyl, and heroin epidemic. Pain Physician 2018; 21:309-326.

22. Kaye AD, Jones MR, Kaye AM, Ripoll JG, Jones DE, Galan V, Beakley BD, Calixto F, Bolden JL, Urman RD, Manchikanti L. Prescription opioid abuse in chronic pain: An updated review of opioid abuse predictors and strategies to curb opioid abuse: Part 2. Pain Physician 2017; 20:S111-S133.

23. Kaye AD, Jones MR, Kaye AM, Ripoll JG, Galan V, Beakley BD, Calixto F, Bolden JL, Urman RD, Manchikanti L. Prescription opioid abuse in chronic pain: An updated review of opioid abuse predictors and strategies to curb opioid abuse: Part 1. Pain Physician 2017; 20:S93-S109.

24. Chakravarthy K, Manchikanti L, Kaye $A D$, Christo PJ. Reframing the role of neuromodulation therapy in the chronic pain treatment paradigm. Pain Physician 2018; 21:507-513.

25. Manchikanti L, Boswell MV, Kaye AD, Helm II S, Hirsch JA. Therapeutic role of placebo: Evolution of a new paradigm in understanding research and clinical practice. Pain Physician 2017; 20:363-386.

26. Greenhalgh T, Howick J, Maskrey N; Evidence Based Medicine Renaissance Group. Evidence based medicine: a movement in crisis? BMJ 2014; 348:g3725.

27. Shen J, Xu S, Xu S, Ye S, Hao J. Fusion or not for degenerative lumbar spinal stenosis: A meta-analysis and systematic review. Pain Physician 2018; 21:1-8.

28. Song D, He A, Xu R, Xiu X, Wei Y. Efficacy of pain relief in different postherpetic neuralgia therapies: A network metaanalysis. Pain Physician 2018; 21:19-32.

29. Manchikanti L, Soin A, Benyamin RM, Singh V, Falco FJ, Calodney AK, Grami V, Hirsch JA. An update of the systematic appraisal of the accuracy and utility of discography in chronic spinal pain. Pain Physician 2018; 21:91-110.

30. Sanapati J, Manchikanti L, Atluri S, Jordan S, Albers SL, Pappolla MA, Kaye AD, Candido KD, Pampati V, Hirsch JA. Do regenerative medicine therapies provide long-term relief in chronic low back pain: A systematic review and metaanalysis. Pain Physician 2018; 21:515-540.

31. Fu X, Tang L, Wang C, Li M, Wu H, Li J, $\mathrm{Ma}$ Q, Yang W. A network meta-analysis to compare the efficacy of steroid and antiviral medications for facial paralysis from Bell's palsy. Pain Physician 2018; 21:559-569.

32. Hou S, Huh B, Kim HK, Kim KH, Abdi S. Treatment of chemotherapy-induced peripheral neuropathy: Systematic review and recommendations. Pain Physician 2018; 21:571-592.

33. Cho JH, Lee $J \mathrm{H}$, Song $\mathrm{KS}$, Hong $\mathrm{JY}$, Joo YS, Lee DH, Hwang CJ, Lee CS. Treatment outcomes for patients with failed back surgery. Pain Physician 2017; 20:E29-E43.

34. Salazar AP, Stein C, Marchese RR, Plentz RD, Pagnussat AS. Electric stimulation for pain relief in patients with fibromyalgia: A systematic review and metaanalysis of randomized controlled trials. Pain Physician 2017; 20:15-25.

35. Gupta A, Huettner DP, Dukewich M. Comparative effectiveness review of cooled versus pulsed radiofrequency ablation for the treatment of knee osteoarthritis: A systematic review. Pain Physician 2017; 20:155-171.

36. Chaichian S, Kabir A, Mehdizadehkashi A, Rahmani K, Moghimi M, Moazzami B. Comparing the efficacy of surgery and medical therapy for pain management in endometriosis: A systematic review and meta-analysis. Pain Physician 2017; 20:185-195.

37. Gudala K, Bansal D, Vatte R, Ghai B, Schifano F, Boya C. High prevalence of neuropathic pain component in patients with low back pain: Evidence from metaanalysis. Pain Physician 2017; 20:343-352.

38. Prusova K, Churcher L, Tyler A, Lokugamage U. Royal College of Obstetricians and Gynaecologists guidelines: How evidence-based are they? J Obstet Gynaecol 2014; 34:706-711.

39. Clark J, Nijs J, Yeowell G, Goodwin PC. What are the predictors of altered central pain modulation in chronic musculoskeletal pain populations? A systematic review. Pain Physician 2017;
20:487-500.

40. Rysavy M. Evidence-based medicine: A science of uncertainty and an art of probability. Virtual Mentor 2013; 15:4-8.

41. Hickey S, Roberts H. Evidence based medicine: Neither good evidence nor good medicine. Orthomolecular Medicine News Service, December 7, 2011.

http://orthomolecular.org/resources/ omns/vo7n15.shtml

42. Schwartz D. Evidence-based medicine is NOT the Holy Grail (Share) - NEW IMPROVED.

https://www.linkedin.com/pulse/evidence-based-medicine-holy-grail-david-schwartz

43. Every-Palmer S, Howick J. How evidence-based medicine is failing due to biased trials and selective publication. J Eval Clin Pract 2014; 20:908-914.

44. Reichman $\mathrm{OH}$, Origitano TC, Anderson DE, Duckworth EA. Lies, damned lies, and statistics: A neurosurgical perspective on the international randomized trial of extracranial to intracranial arterial bypass surgery. J Stroke Cerebrovasc Dis 2009; 18:389-397.

45. Cappola AR, FitzGerald GA. Confluence, not conflict of interest: Name change necessary. JAMA 2015; 314:1791-1792.

46. David Eddy created the Archimedes model to predict and analyze care. Health Aff (Millwood) 2012; 31:2451-2452.

47. Mercuri M, Baigrie B, Upshur REG. Going from evidence to recommendations: Can GRADE get us there?] Eval Clin Pract 2018; 24:1232-1239.

48. Howick J. The evidence-based medicine renaissance: Holy grail or poisoned chalice? BMC Blog Netowrk, July 3, 2014.

https://blogs.biomedcentral.com/onmedicine/2014/07/03/the-evidencebased-medicine-renaissance-holy-grailor-poisoned-chalice/

49. Packer M. Are meta-analyses a form of medical fake news? Thoughts about how they should contribute to medical science and practice. Circulation 2017; 136:2097-2099.

50. Foroutan F, Guyatt G, Alba AC, Ross H. Meta-analysis: mistake or milestone in medicine? Heart 2018; 104:1559-1561.

51. Mercuri M, Gafni A. The evolution of GRADE (part 2): Still searching for a theoretical and/or empirical basis for the GRADE framework. J Eval Clin Pract 2018; 24:1211-1222. 
52. Shekelle PG. Clinical practice guidelines: What's next? JAMA 2018; 320:757-758.

53. Riado Minguez $D$, Kowalski M, Vallve Odena M, Longin Pontzen D, Jelicic Kadic A, Jeric M, Dosenovic S, Jakus D, Vrdoljak M, Poklepovic Pericic T, Sapunar D, Puljak L. Methodological and reporting quality of systematic reviews published in the highest ranking journals in the field of pain. Anesth Analg 2017; 125:1348-1354.

54. Ross A, Rankin J, Beaman J, Murray K, Sinnett P, Riddle R, Haskins J, Vassar M. Methodological quality of systematic reviews referenced in clinical practice guidelines for the treatment of opioid use disorder. PLoS One 2017; 12:e0181927.

55. Schussel V, Kenzo L, Santos A, Bueno J, Yoshimura E, de Oliveira Cruz Latorraca C, Pachito DV, Riera R. Cannabinoids for nausea and vomiting related to chemotherapy: Overview of systematic reviews. Phytother Res 2018; 32:567-576.

56. Pussegoda K, Turner L, Garritty C, Mayhew A, Skidmore B, Stevens A, Boutron I, Sarkis-Onofre R, Bjerre LM, Hróbjartsson A, Altman DG, Moher D. Systematic review adherence to methodological or reporting quality. Syst Rev 2017; 6:131.

57. Tafelski S, Häuser W, Schäfer M. Efficacy, tolerability, and safety of cannabinoids for chemotherapy-induced nausea and vomiting--a systematic review of systematic reviews. Schmerz 2016; 30:14-24.

58. Gagnier JJ, Kellam PJ. Reporting and methodological quality of systematic reviews in the orthopaedic literature. J Bone Joint Surg Am 2013; 95:e771-E777.

59. A Measurement Tool to Assess Systematic Reviews (AMSTAR). https://amstar.ca/

6o. Manchikanti L, Manchikanti KN, Gharibo CG, Kaye AD. Efficacy of percutaneous adhesiolysis in the treatment of lumbar post surgery syndrome. Anesth Pain Med 2016; 6:e26172.

61. Brito-García N, García-Pérez L, Kovacs FM, Del Pino-Sedeño T, Pérez-Ramos J, Imaz-Iglesia I, Serrano-Aguilar P. Efficacy, effectiveness, safety, and costeffectiveness of epidural adhesiolysis for treating failed back surgery syndrome. A systematic review. Pain Med 2019; 20: 692-706.

62. Epter RS, Helm S, Hayek SM, Benyamin RM, Smith HS, Abdi S. Systematic review of percutaneous adhesiolysis and management of chronic low back pain in post lumbar surgery syndrome. Pain Physician 2009; 12:361-378.

63. Chun-jing $\mathrm{H}$, Hao-xiong $\mathrm{N}$, Jia-xiang $\mathrm{N}$. The application of percutaneous lysis of epidural adhesions in patients with failed back surgery syndrome. Acta Cir Bras 2012; 27:357-362.

64. Manchikanti L, Singh V, Cash KA, Pampati $V$, Datta S. Assessment of effectiveness of percutaneous adhesiolysis and caudal epidural injections in managing lumbar post surgery syndrome: A 2-year follow-up of randomized, controlled trial. J Pain Res 2012; 5:597-608.

65. Gerdesmeyer L, Wagenpfeil S, Birkenmaier C, Veihelmann A, Hauschild M, Wagner K, Muderis MA, Gollwitzer $H$, Diehl P, Toepfer A. Percutaneous epidural lysis of adhesions in chronic lumbar radicular pain: A randomized, double-blind, placebo-controlled trial. Pain Physician 2013; 16:185-196.

66. Heavner JE, Racz GB, Raj P. Percutaneous epidural neuroplasty: Prospective evaluation of $0.9 \%$ nacl versus $10 \%$ nacl with or without hyaluronidase. Reg Anesth Pain Med 1999; 24:202-207.

67. Veihelmann A, Devens C, Trouillier $H$, Birkenmaier C, Gerdesmeyer L, Refior HJ. Epidural neuroplasty versus physiotherapy to relieve pain in patients with sciatica: A prospective randomized blinded clinical trial. J Orthop Sci 2006; 11:365-369.

68. Manchikanti L, Cash KA, McManus CD, Pampati V. Assessment of effectiveness of percutaneous adhesiolysis in managing chronic low back pain secondary to lumbar central spinal canal stenosis. Int J Med Sci 2013; 10:50-59.

69. Manchikanti L, Rivera JJ, Pampati V, Damron KS, McManus CD, Brandon $D E$, Wilson SR. One day lumbar epidural adhesiolysis and hypertonic saline neurolysis in treatment of chronic low back pain: A randomized, double-blind trial. Pain Physician 2004; 7:177-186.

70. Kumar K, Taylor RS, Jacques L, Eldabe S, Meglio M, Molet J, Thomson S, O'Callaghan J, Eisenberg E, Milbouw G, Buchser E, Fortini G, Richardson J, North RB. The effects of spinal cord stimulation in neuropathic pain are sustained: A 24-month follow-up of the prospective randomized controlled multicenter trial of the effectiveness of spinal cord stimulation. Neurosurgery 2008; 63:762-770; discussion 770 .
71. North RB, Kidd DH, Farrokhi F, Piantadosi SA. Spinal cord stimulation versus repeated lumbosacral spine surgery for chronic pain: A randomized, controlled trial. Neurosurgery 2005; 56:98-106; discussion 107.

72. Frey ME, Manchikanti L, Benyamin RM, Schultz DM, Smith HS, Cohen SP. Spinal cord stimulation for patients with failed back surgery syndrome: A systematic review. Pain Physician 2009; 12:379-397.

73. Karm MH, Choi SS, Kim DH, Park JY, Lee S, Park JK, Suh YJ, Leem JG, Shin JW. Percutaneous epidural adhesiolysis using inflatable balloon catheter and balloon-less catheter in central lumbar spinal stenosis with neurogenic claudication: A randomized controlled trial. Pain Physician 2018; 21:593-606.

74. Akbas $M$, Elawamy AR, Salem $\mathrm{HH}$, Fouad AZ, Abbas NA, Dagistan G. Comparison of 3 approaches to percutaneous epidural adhesiolysis and neuroplasty in post lumbar surgery syndrome. Pain Physician 2018; 21:E501-E508.

75. Hossieni B, Dadkhah P, Moradi S, Hashemi SM, Safdari F. The results of treating failed back surgery syndrome by adhesiolysis: Comparing the one- and three-day protocols. Anesth Pain Med 2017; 7:e60271.

76. Furlan AD, Pennick V, Bombardier C, van Tulder M. 2009 updated method guidelines for systematic reviews in the Cochrane back review group. Spine (Phila Pa 1976) 2009; 34:1929-1941.

77. Manchikanti L, Hirsch JA, Cohen SP, Heavner JE, Falco FJE, Diwan S, Boswell MV, Candido KD, Onyewu O, Zhu J, Sehgal N, Kaye AD, Benyamin RM, Helm II S, Singh V, Datta $S$, Abdi S, Christo PJ, Hameed $\mathrm{H}$, Hameed M, Vallejo R, Pampati V, Racz GB, Raj PP. Assessment of methodologic quality of randomized trials of interventional techniques: Development of an interventional pain management specific instrument. Pain Physician 2014; 17:E263-E290.

78. Harbour R, Miller J. A new system for grading recommendations in evidence based guidelines. BM] 2001; 323:334-336.

79. Manchikanti L, Falco FJE, Benyamin RM, Kaye AD, Boswell MV, Hirsch JA. A modified approach to grading of evidence. Pain Physician 2014; 17:E319-E325.

8o. West S, King V, Carey TS, Lohr KN, McKoy N, Sutton SF. Lux L. Systems to rate the strength of scientific evidence. Evid Rep Technol Assess (Summ) 2002; 47:1-11. 
81. Thomson S. Failed back surgery syndrome - definition, epidemiology and demographics. Br J Pain 2013; 7:56-59.

82. Manchikanti L, Helm S 2nd, Pampati $V$, Racz GB. Cost utility analysis of percutaneous adhesiolysis in managing pain of post-lumbar surgery syndrome and lumbar central spinal stenosis. Pain Pract 2015; 15:414-422.

83. Manchikanti L, Falco FJE, Pampati V, Cash KA, Benyamin RM, Hirsch JA. Cost utility analysis of caudal epidural injec- tions in the treatment of lumbar disc herniation, axial or discogenic low back pain, central spinal stenosis, and post lumbar surgery syndrome. Pain Physician 2013; 16:E129-E143.

84. Manchikanti L, Pampati V, Kaye AD, Hirsch JA. Cost utility analysis of cervical therapeutic medial branch blocks in managing chronic neck pain. Int J Med Sci 2017; 14:1307-1316.

85. Manchikanti L, Pampati V, Kaye AD, Hirsch JA. Therapeutic lumbar facet joint nerve blocks in the treatment of chronic low back pain: Cost utility analysis based on a randomized controlled trial. Korean J Pain 2018; 31:27-38.

86. Manchikanti L, Pampati V, Benyamin RM, Hirsch JA. Cost utility analysis of lumbar interlaminar epidural injections in the treatment of lumbar disc herniation, central spinal stenosis, and axial or discogenic low back pain. Pain Physician 2017; 20:219-228. 